\title{
Effect of Enamel Matrix Derivative on Alkaline Phosphatase Activity in Osteoblast Cells Through the Mitogen-activated Protein Kinase Pathway
}

\author{
Zhe Qu \\ Department of Implantology School of Stomatology \\ name of organization \\ Dalian University \\ Dalian, China \\ E-mail: Quzhekq@hotmail.com
}

Ling Tang

School of Life Science and Technology

Dalian University

E-mail: tangyuling6688@163.com

Ying Guo

Department of Prosthodontics

School of Stomatology

Dalian University,

Dalian, China

E-mail: Guohining@hotmail.com

\author{
Wei Dong Ma \\ Department of Implantology School of Stomatology \\ name of organization \\ Dalian University \\ Dalian, China \\ E-mail: Dlkqma@163.com
}

\author{
Jingying Zhang* \\ School of Medicine \\ Dalian University \\ E-mail:jingyingzhang2014@foxmail.com \\ *Corresponding author:Jingying Zhang
}

\begin{abstract}
The study examined the response of MG63 to Enamel Matrix Derivative (EMD) on the coarse-grit-blasted and acid-etched surface disks. We characterized associated changes in proliferation and differentiation related intracelluar signaling molecular including mitogen activitied protein kibase. The major groups of MAPKs (ERK1/2, cJUN-terminal kinases, JNK and p38-MAPK) have been characterized in previous experiments. We will check which pathways stimulate the proliferation and differentiation of MG63 on the coarse-grit-blasted and acid-etched surface disks by the western blot. EMD regulated the proliferation and differentiation of MG63 on the coarse-grit-blasted and acid-etched surface disks. EMD inhibit the cell proliferation of MG63, increase the differentiation of MG63 and production of osteocalcin and TGF- $\beta 1$. The signaling pathway induced by END from ERK1/2 JNK and p38 were detected. EMD has been successfully used to affect the proliferation and differentiation of osteoblast on the surface of implants. EMD can accelerate the regeneration of soft and hard tissue in the peri-implantitis disease. EMD can be used in the pero-implantitis disease to regenerate the soft and hard tissue.
\end{abstract}

Keywords-Enamal matrix; periodontal regeneration; MG63 ; perio-implantitis ; MAPK

\section{INTRODUCTION}

Following the titanium (Ti) dental implant extensive to apply in periodontology surgery and implant surgery. It has been sticking point how to construct a stable connection structure between the oral bone and the surface of the dental implant. Last few years, the surface properties of dental implant such as topography or chemistry play a critical role in the establishment of cell-biomaterials interfaces. Looking at the interface from the perspective of implant materials, a current key question is how the material's surface influences the biological response and how the biosystem itself influences the surface properties of a given biomaterial. Now more scholars are interested in the application of biology matrix poteins to enhance the regeneration on the surface of implants ${ }^{[1]}$. Protein adsorption will modulate the chemical and biology properties of Ti dioxide and cells attachment.

EMD in the form of a purified acid extract of proteins from pig enamel matrix has been successfully and widely applied in promoting periodontal tissue regeneration in recent studies ${ }^{[2]}$. Its osteogenetic activities have been shown in the repair of periodontal intrabony defects in alveolar bone and in experimental bone defects in animal models ${ }^{[3]}$. A great many of literature show EMD may have the capacity to stimulate formation not only of new cementun and new periodontal ligament fiber, but also new bone. It has been shown that EMD effect the cells of periodontal tissues the proliferation and differentiation, such as periodontal ligament cells, alveolar osteoblasts, and epithelial cells ${ }^{[4]}$.

In animal experiments, the results suggest EMD is an effective biology matrix for enhancing new trabecular bone induction and resulting attachment of orthopedic 
prostheses to the recipient bone ${ }^{[5]}$. Cells respond to extracellular stimuli by engaging specific intracellular programs, such as signaling cascade that leads to activation of the mitogen-activated protein kinases (MAPKs). All eukaryotic cells possess multiple MAPK pathways, which coordinately regulate diverse cellular activities running the gamut from gene expression, mitosis, metabolism, survival and apoptosis and differentiation. Five distinct groups of MAPKs have been characterized in mammals: extracellular signal-regulated kinases (ERKs) 1 and 2 ( ERK1/2), c-JUN amino-terminal kinases ( junks ) 1,2 and $3, \mathrm{p} 38$ idoforms $\alpha, \beta, \gamma$ and $\delta$, ERKs 3 and 4 , and ERK5. The most extensively studied groups of vertebrate MAPKs to date are the ERK1/2, JNKs and p38 kinases ${ }^{[6]}$.

The aim of this study was to observe the effect of EMD to proliferation and differentiation of osteoblasts, further detect the signaling molecules and pathways responsive in the osteoblasts through EMD on the surface of the implants.

\section{PREPARATION OF THE TITANIUM SURFACE}

We select the Ti implants which have been widely applied commercially as the dental implants in the clinic at present. The disks size is $15 \mathrm{~mm}$ in diameter and $1 \mathrm{~mm}$ in thickness of the Ti. The coarse-grit-blasted and acid-etched (SLA) surface was prepared. Degreasing and acidprepickling by washing in acetone, processing through a $2 \%$ ammonium fluoride $/ 2 \%$ hydrofluoride acid $/ 10 \%$ nitric acid solution at $5{ }^{\circ} \mathrm{C}$ for $30 \mathrm{~s}$, and pickling in $2 \%$ hydrofluoric acid $/ 10 \%$ nitric acid at room temperature for $30 \mathrm{~s}$, preparing with $0.2-0.5 \mu \mathrm{m}$ corundum grit at 5 bars until the surface reached a uniform gray tone. Then the surfaces were acid-etched in hydrochloric acid/sulfuric acid. After the preparation of the surface, the disks were rinsed with deinized water, neutralized in a 5\% sodium bicarbonate solution, ultrasonically rised in deionized water for three 5-min periods, and sterilized by autoclaving.

\section{A. Chemicals}

EMD with the vehicle gel propylene glycol alginate (Emdogain $\AA$, EMD, BIORA AB, malmö, Sweden) is diluted by in Modified Eagle Medium (MEM) with 1\% penicillin/streptomycin, the EMD stock concentration is 1 $\mathrm{mg} / \mathrm{ml}$. Antibodies were used included those recognizing ERK1/2, JNK, p38, ERK $1 / 2$ phosphorylated, JNK dually phosphorylated and p38 phosphorylated. All antibodies: polyclonal anti-phosphorylated extracellular signal resonse kinase 1/2 (ERK) antibody and polyclonal anti-ERK antibody were obtained from Chemicon international institution, California in USA; polyclonal antiphosphorylated p38 antibody, monoclonal anti-p38 antibody, polyclonal anti-phosphorylated JNK antibody, and monoclonal anti-JNK antibody were obtained from Santa cruz Biotechnology institution CA in USA.

\section{B. Cell culture}

MG-63 osteoblast-like cells were obtained from the American type culture collection (Rockville, MD). MG-63 cells were originally isolated from a human osteosarcoma. Cultures were maintained in Modified Eagle Minimum essential Medium (MEM, Gibco, Cananda) supplemented with $10 \%$ fetal Bovine serum (FBS, Gibco, Cananda) and
$1 \%$ penicillin/streptomycin (FBS, Gibco,Cananda). Until confluent, cells were passaged at a 1:4 split ratio following trypsinization with $0.05 \%$ trypsin (1:250)-0.53mM tetrasodium ethylenediaminetetraacetic acid (EDTA, PAA, Austria). All experiments were performed using cells between the third and seven passages. Cell numbers were determined using a Coulter counter (Coulter, Hialeah, FL). Cells harvested in this manner exhibited $>95 \%$ viability based on Trypan blue exclusion. MG63 cells were grown on $15 \mathrm{~mm}$ SLA surface Ti discs in 24 well cell culture plates, such that in every experiment, each variable was tested using six separate disks with one disk per well. The cells were plated at a seeding density of 9600 cells $/ \mathrm{cm}^{2}$. Medium was removed after $24 \mathrm{~h}$, and then changed at $48 \mathrm{~h}$ intervals. After cells reached confluence, the media was replaced in all culture. Cells grown on $\mathrm{Ti}$ disks were treated with experimental media containing $50 \mu \mathrm{g} / \mathrm{ml}$ or $100 \mu \mathrm{g} / \mathrm{ml}$ Emdogain ${ }^{\circledR}$, the positive control were treated with experimental media containing $1 \alpha, 25(\mathrm{OH})_{2} \mathrm{D}_{3}$ (Alexis ${ }^{\circledR}$ Biochemicals corporation, Lausen, Switzerland), and the negative control were treated with the normal media. The culture were continued for an additional $48 \mathrm{~h}$.Then the further assays were performed.

\section{Cell number}

To determine if the cell number was mediated by Emdogain ${ }^{\circledR}$ dependent, the experimental media contains the concentration of Emdogain ${ }^{\circledR}$ is $12.5,25,50,100 \mu \mathrm{g} / \mathrm{ml}$ and $1 \alpha, 25(\mathrm{OH}) 2 \mathrm{D} 3$. The cell number was assessed by the cell counting kit-8 assays (Dojido Laboratories, Japan). Add $50 \mu \mathrm{l}$ of CCK-8 solution to each well of plate, and incubate the plate for 4 hours in incubator, then measure the absorbance at $450 \mathrm{~nm}$ using a micro-plate reader with a reference wavelength at $650 \mathrm{~nm}$.

\section{Alkaline phosphatase specific activity}

Cell layers were added to the sample lyse buffer with $0.2 \%$ triton and homogenized via sonification. After lysing the cells, protein content was determined using a commercially available kit (Micro/Macro BCA; Pierce Chemical Co., Rockford, IL). The Alkaline phosphatase specific activity was measured colorimetrically using pnitrophenyl phosphate as a substrate. The enzyme ALP expressed by the cells hydrolyzes the substrate to pnitrophenol and an inorganic phosphate. Under alkaline conditions, the p-nitrophenol was converted to a yellow product and its absorbance was subsequently measured at $450 \mathrm{~nm}$ using a spectrophotometer. Activity was assayed at $37^{\circ} \mathrm{C}$ as the release of $\mathrm{p}$-nitrophenol from $\mathrm{p}$ nitrophenylphosphate at $\mathrm{pH} 10.2$.

\section{E. Osteocalcin}

The production of osteocalcin by the cultures was measured by an enzyme-linked immunosorbent assay (ELISA, Biosource international, Inc., USA). Twenty-five microliter of the sample media was placed into the microtiter plate with 96 anti-hu OST coat wells plate, and pipette $100 \mu \mathrm{l}$ of anti-hu OST conjugate into all the wells, and incubate for 2 hours at room temperature on a horizontal shaker set at $700 \pm 100 \mathrm{rpm}$. After washing with PBS for three times, $100 \mu \mathrm{l}$ of freshly prepared, chromogenic agent was added to each well and incubated for 30 minutes at room temperature, which was then followed by adding $200 \mu \mathrm{l}$ of stop solution. The 
absorbance was measured at $450 \mathrm{~nm}$ against the reference filter set at $650 \mathrm{~nm}$. Osteocalcin concentrations were determined by correlating the percentage of bound-overunbound counts to a standard curve.

\section{F. $T G F-\beta 1$}

In order to measure the level of total TGF- $\beta 1$ in the conditioned media at time of harvest, a commercially available enzyme-linked immunosorbent assay kit (R\&D systems, inc., Minneapolis, USA) was used. Immediately prior to assay, conditioned media were acidified to activate latent TGF- $\beta$, and the assay was performed according to the manufacturer's directions. The amount of TGF- $\beta 1$ in the cell layer was not examined because of difficulties associated with quantitatively extracting this growth factor from the matrix when using samples of this size. Approximately $20 \%$ of total TGF- $\beta 1$ produced by the MG63 cells on plastic is in the cell layer.

\section{G. Western blot}

The MG63 cells were cultured on the SLA Ti disks in the $100 \mu \mathrm{g} / \mathrm{ml}$ Emdogain $\AA$ in $0.5 \%$ FBS for 15, 30, $60 \mathrm{~min}$ or 24 hours. The cells were once washed with chilled PBS, lyzed in a modified Ridioimmunoprecipitation assay(RIPA) buffer and then homogenized via sonification17.Total proteins $(-50 \mu \mathrm{g})$ were separated by $10 \%$ Sodium dodeccyl sulfate-polyacrylamide gel electrophoresis(SDS-PAGE) under reduced conditions and were then transferred to hybondTM-ECLTM nitrocellulose membranes (Amersham Biosciences, Germany) using transfer buffer at $350 \mathrm{v}$ for 50 minutes. After blocking $2 \%$ skimmed milk, the target protein were detected by probing with the follow primary antibody: polyclonal anti-phosphorylated extracellular signal resonse kinase $1 / 2$ (ERK) antibody (1:1000; Chemicon international Inc., California , USA), polyclonal anti-ERK antibody $(1: 1000$, Chemicon international Inc.), polyclonal anti-phosphorylated p38 antibody(1:1000; Santa cruz Biotechnology Santa Cruz, CA, USA ), monoclonal anti-p38 antibody (1:1000; Santa Cruz Bio-technology), polyclonal anti-phosphorylated JNK antibody (1:1000; Santa Cruz Bio-technology,), and monoclonal anti-JNK antibody $(1: 1000$, Santa Cruz Biotechnology). After the members were washed for three times by TBS-T buffer, and reacted with horseradish peroxidase (HRP)-conjugated Rabbit Anti-mouse OR Goat Anti-rabbit immunologlobulins (1:2000; DAKO A/s Denmark), followed by visualization with the Amersham ECL plus western blottingdetection system (Amersham Biosciences, Germany). The experiments were performed three times and representative results are shown.

\section{H. Statistical analysis}

For cell culture studies, datum is presented from one of three separate experiments, all of which yield comparable result. For any given experiment, each value represents the mean plus or minus the standard error of the mean of six individual cultures (mean $\pm \mathrm{SD}$ ). The datum was analyzed by an analysis of variance, and the statistical significance was determined with Bonferroni's modification of the student $t$ test or one way ANOVA. P values less than or equal to 0.05 were considered significant.

\section{RESULT}

\section{A. Proliferation}

Enamel matrix derivative inhibited the cell proliferation of MG63 cells in the dose-dependent manner at concentrations greater than $100 \mu \mathrm{g} / \mathrm{ml}$. The dosedependent of EMD is shown in the cell number variable, the relative ratio $(\mathrm{R})$ is 0.975 (Fig .1). The difference was statistics significant from control at the other concentration. $1 \alpha, 25(\mathrm{OH})_{2} \mathrm{D}_{3}$ decrease the cell number on the SLA disk.

\section{B. Cell differentiation}

There were distinctly increase in alkaline phosphatase activity, osteocalcin production and TGF- $\beta 1$ level with the high concentration $100 \mu \mathrm{g} / \mathrm{ml}$ of EMD on the SLA surface disk. We selected the $10-7 \mathrm{M} 1 \alpha, 25(\mathrm{OH})_{2} \mathrm{D}_{3}$ as the positive. As it is known, the $10-7 \mathrm{M} 1 \alpha, 25(\mathrm{OH})_{2} \mathrm{D}_{3}$ accelerate the cell differentiation of the osteoblasts. Alkaline Phosphatase activity and osteocalcin production are greater with the concentration $50 \mu \mathrm{g} / \mathrm{ml}$ of EMD stimulation than with $10-7 \mathrm{M} 1 \alpha, 25(\mathrm{OH})_{2} \mathrm{D}_{3}$ stimulation in the MG63 cell cultures on the SLA surface. But TGF- $\beta 1$ level is not much different between the concentration $50 \mu \mathrm{g} / \mathrm{ml}$ of EMD stimulation and $10-7 \mathrm{M} 1 \alpha, 25(\mathrm{OH}) 2 \mathrm{D} 3$ stimulation. But all the stimulation group is higher than the control (Fig .2, Fig .3 and Fig .4).

\section{Western blot}

It has been demonstrated that the activation of the membrane receptors associated with Rho-mediated action polymerization can simultaneously lead to activation of MAPK cascade ${ }^{[7]}$. The side range of fuctions of the MAPKs are mediated through phosphorylation of several substrates, including phospholipases, transcription factor and cytoskeletal protein. Phosphorylation of the MAPK in MG63 was detected by the western blot with the antibodies to phosphorylated MAPK. The degree of phosphorylated $44 \mathrm{kDa}$ ERK 1 and $42 \mathrm{kDa}$ ERK 2 increased rapidly in 30 minutes following exposure to the concentration $100 \mu \mathrm{g} / \mathrm{ml}$ of EMD stimulation, and then gradually decrease in one hour. The effect persists to 24 hours. As report previously, ERK1/2 MAPK is required for the maintenance of alkaline phosphatase at control levels and that of effects of $1 \alpha, 25(\mathrm{OH})_{2} \mathrm{D}_{3}$ are mediated by ERK1/221. So $1 \alpha, 25(\mathrm{OH})_{2} \mathrm{D}_{3}$ also caused phosphorylated of ERK1/2 as positive control. However, the effects of surface roughness are not due to the ERK family of MAPK14. In contrast, JNK and p38 were detected, but phosphorylated of JNK and p38 were not detectable (Fig .5). The result shown EMD do not have effect by phosphorylated way of JNK and $\mathrm{p} 38$.

\section{DISCUSSION}

EMD is prepared from developing porcine tooth buds and is relative to important biological function in tooth development and periodontal regeneration. In the Previous report, the experiment results in vivo show EMD stimulate the differentiation of the human periodotal ligament cells, primary osteoblast cells and MG 63. However, EMD increase the proliferation of the human periodotal ligament cells and primary osteoblasts, decrease the proliferation of MG 63. The results of the animal experiment and several clinical trials in vitro indicate that EMD has the ability to 
induce the regeneration of the periodontal tissue, cementum, PDL and alveolar bone, So The EMD can be used the treatment of intrabony defect, since horizontal bone loss defects are not likely to exhibit a successful outcome with regenerative treatment ${ }^{[8]}$.

Following the implant surgery is popular in clinics, peri-implantitis surrounding oral implants is an inflammatory process affecting the soft and hard tissues resulting in rapid loss of supporting bone associated with bleeding and suppuration. So the therapeutical approach of peri-implantitis surrounding dental implants comprises several aspects such as the removal of supra-gingival bacterial plaque, an appropriate surgical approach, the removal of granulation tissue and detoxification of the exposed implant surface, the elimination of the anaerobic ecosystem by the removal of peri-implant pocket or by the regeneration of peri-implant hard tissue and finally, the establishment of an efficient plaque control regimen. So we try to use the EMD in the pero-implantitis disease to regenerate the soft and hard tissue.

The results of this study indicate the effect of EMD to MG63 cells assessed on the SLA surface disks. EMD inhibit the cell proliferation of MG63 on the SLA surface disks with the cell number counting kit, and the cell proliferation show the dose depend of EMD. To the differentiation of MG63, we select the objects as alkaline phosphatase, osteocalcin and TGF- $\beta 1$. $10-7 \mathrm{M}$ $1 \alpha, 25(\mathrm{OH})_{2} \mathrm{D}_{3}$ was selected as the positive control. The concentration of EMD $100 \mu \mathrm{g} / \mathrm{ml}$ stimulate the differentiation of MG63, the results of alkaline phosphatase, osteocalcin and TGF- $\beta 1$ are the highest than the $10-7 \mathrm{M} 1 \alpha, 25(\mathrm{OH}) 2 \mathrm{D} 3$ group and the $50 \mu \mathrm{g} / \mathrm{ml}$ concentration of EMD. To osteocalcin and TGF- $\beta 1$, the $10-7 \mathrm{M} 1 \alpha, 25(\mathrm{OH}) 2 \mathrm{D} 3$ group and the $50 \mu \mathrm{g} / \mathrm{ml}$ concentration of EMD are different, and the result is not significative. The alkaline phosphatase activity is higher in the $50 \mu \mathrm{g} / \mathrm{ml}$ concentration of EMD group than the $100 \mu \mathrm{g} / \mathrm{ml}$ concentration of EMD group. These results suggest that END has characteristics similar to factor like $1 \alpha, 25(\mathrm{OH}) 2 \mathrm{D} 3$, BMP and TGF- $\beta$. All results indicate EMD is an osteo-conductive agent and that EMD can be used in the perio-implantitis regeneration.

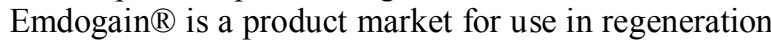
periodontal tissue based on the concept that E-M interaction are required for formation of cementum. EMD is an extract of low molecular weight porcine enamel proteins, containing predominantly amelogenin, and thus, the activity noted has been attributed to amelogenin. So EMD contains other bioactive factors and many vary between preparations. To expatiate the MAPK mechanism of EMD to simulate the osteoblasts on the surface of implants, It is known that MAPKs can be activated by a wide variety different stimuli, but in general, ERK1 and ERK2 are preferentially activated in response to growth factors and phorbol esters, while the JNK and p38 kinases are more responsive to stress stimuli ranging from osmotis shock and ionizing radiation to cytokine stimulation ${ }^{[9]}$. Spatiotemporal control of the RAs/ERK MAP kinase signaling pathway is a key factor for determining the specificity of cellular responses including cell proliferation, cell differentiation and cell survival ${ }^{[10]}$. MAPK cascade specificity is also mediated through interaction with scaffolding protein which organized pathways in specific modules through simultaneous binding of several components. In addition, it is widely accepted that the ERK cascade mediates many proliferative effects and that p38-K pathway is involved in apoptotic cell death and /or growth-arrest ${ }^{[11]}$. Our Weston-blot results show EMD effect the proliferation and differentiation of MG63 by the ERK1/2 way in the MAPK family. However the phosphorylation of JNK and p38 are not so many changes by the stimulate of EMD. So we can know EMD effect the proliferation and cell differentiation of osteoblasts by the ERK1/2 way on the SLA surface disks. In addition to these membrance-mediated signaling pathways, EMD exerts the effects on osteoblasts on the surface of implants via traditional nuclear receptor, providing further opportunities for synergism.

In all results of the present study, EMD has been successfully used to effect the proliferation and differentiation of osteoblasts on the surface of implant. On the surface of the implant, we focus the EMD play pathway indirectly regulating cellular functions through the production and secretion of autocrine growth factor such as EGF, TGF- $\beta$, IL-6 and PDGF by the ERK pathway. We can conclude EMD can accelerate the regeneration of soft and hard tissue in the peri-implantitis disease. Further research should be required to evaluate the effect of EMD treatment to peri-implantitis disease by the animal experiments and clinic trials.

\section{ACKNOWLEDGMENT}

The work was supported by the Liaoning Province Department of Education Foundation in China (2013481), Dalian Science and Scientific Research Fund of China Postdoctoral Science Foundation (2014M551097).

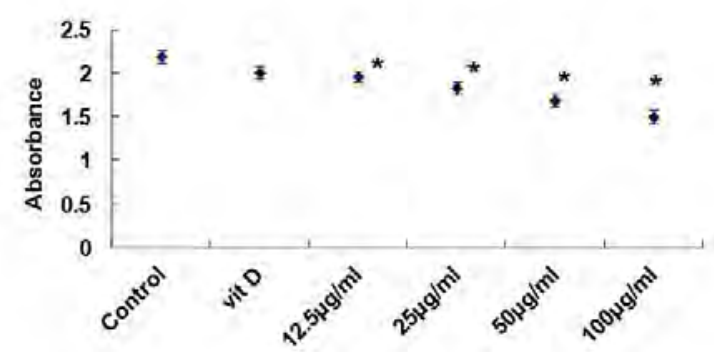

Figure 1. Effect of Emdogain on the cell number.

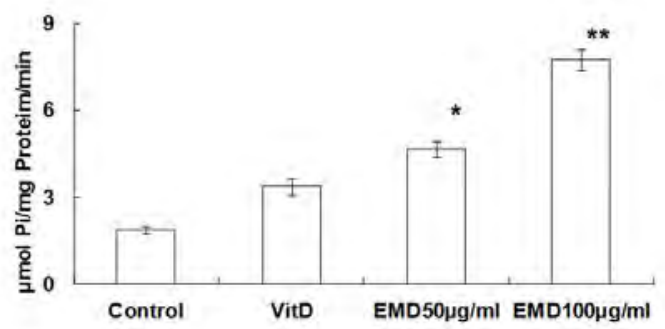

Figure 2. Effect of Emdogain on the alkaline phosphatase activity of MG63. 


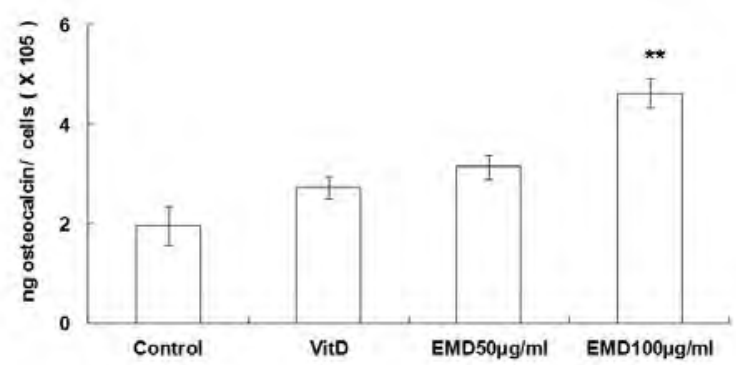

Figure 3. Effect of Emdogain on the osteocalcin production of MG63.

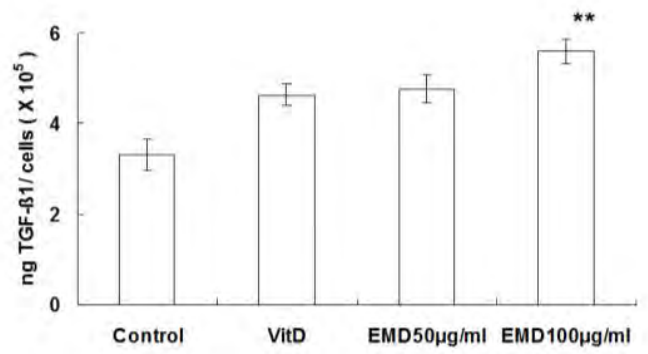

Figure 4. Effect of Emdogain on the TGF- $\beta 1$ level of MG63.

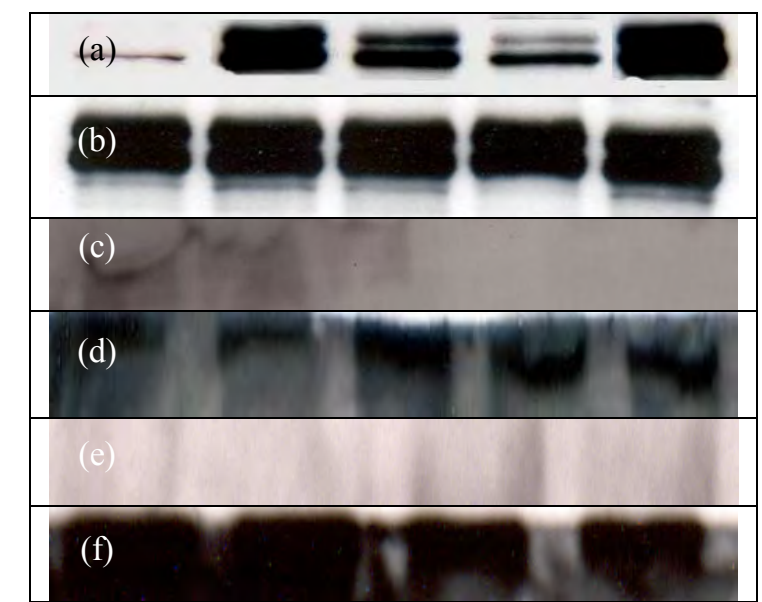

Figure 5. Effect of EMD on the phosphorylation of MAPK family in MG63:(a) P-ERK (b) ERK(c) p-JNK (d) JNK(e) p-P38 (f) P38

\section{REFERENCES}

[1] Zhang BG, Myers DE, Wallace GG, Brandt M, Choong PF. Bioactive coatings for orthopaedic implants-recent trends in development of implant coatings. Int J Mol Sci. 2014 Jul 4; 15(7),pp.11878-921.

[2] Reynolds MA, Kao RT, Camargo PM, Caton JG, Clem DS, Fiorellini JP, Geisinger ML, Mills MP, Nares S, Nevins ML. Periodontal Regeneration: Intrabony Defects: A Consensus Report. J Periodontol. 2014 ,pp. 1-5.

[3] Döri F, Arweiler N, Húszár T, Gera I, Miron RJ, Sculean A. Fiveyear results evaluating the effects of platelet-rich plasma on the healing of intrabony defectstreated with enamel matrix derivative and natural bone mineral. J Periodontol. 2013,pp.1546-55.

[4] Miron RJ, Bosshardt DD, Hedbom E, Zhang Y, Haenni B, Buser $\mathrm{D}$, Sculean A. Adsorption of enamel matrix proteins to a bovinederived bone grafting material and its regulation ofcell adhesion, proliferation, and differentiation. Periodontol. 2012 ,pp.936-47.

[5] Rathe F, Junker R, Chesnutt BM, Jansen JA. The effect of ename matrix derivative (Emdogain) on bone formation: a systematic review. Tissue Eng Part B Rev. 2009 ,pp.215-24.

[6] Strand DW, Liang YY, Yang F, Barron DA, Ressler SJ, Schaue IG, Feng XH, Rowley DR. TGF- $\beta$ induction of FGF-2 expression in stromal cells requires integrated smad 3 and MAPK pathways. Am J Clin Exp Urol. 2014,pp.239-48.

[7] Palanivel R1, Ganguly R1, Turdi S1, Xu A2, Sweeney G3. Adiponectin stimulates Rho-mediated actin cytoskeleton remodeling and glucose uptake via APPL1 in primary cardiomyocytes. Metabolism. 2014,pp.1363-73.

[8] Ogihara S, Tarnow DP. Efficacy of enamel matrix derivative with freeze-dried bone allograft or demineralized freeze-dried bone allograft in intrabony defects: a randomized trial. J Periodontol. 2014,pp.1351-60.

[9] Cavet ME, Harrington KL, Vollmer TR, Ward KW, Zhang JZ. Anti-inflammatory and anti-oxidative effects of the green tea polyphenol epigallocatechin gallate in human corneal epithelial cells. Mol Vis. Feb 2011,pp.533-42.

[10] Jin HS, Liao L, Park Y, Liu YC. Neddylation pathway regulates Tcell function by targeting an adaptor protein She and a protein kinase Erk signaling. Proc Natl Acad Sci U S A. Jan 2013,pp.624-9.

[11] Kawase T, Okuda K, Momose M, Kato Y, Yoshie H, Burns DM. Enamel matrix derivative (EMDOGAIN) rapidly stimulates phosphorylation of the MAP kinase family and nuclear accumulation of smad2 in both oral epithelial and fibroblastic human cells. J Periodontal Res. Dec 2001,pp.367-76. 